\title{
OCORRÊNCIA DE Migdolus fryanus (COLEOPTERA: CERAMBYCIDAE) EM PLANTIOS DE Pinus caribaea var. hondurensis ${ }^{1}$
}

\author{
Carlos Frederico Wilcken ${ }^{2}$, Cassiano Orlato ${ }^{1}$ e Angelo Luiz Tadeu Ottati ${ }^{2}$
}

\begin{abstract}
RESUMO - Larvas de Migdolus fryanus Westwood (Coleoptera: Cerambycidae) foram encontradas danificando raízes de mudas de $P$. caribaea var. hondurensis (Sénéel) Barr. \& Golf. no Estado de São Paulo. Isso aumenta a importância dessa espécie, cujos danos, em espécies florestais, têm aumentado, principalmente, em plantios de eucalipto. Esse é o primeiro registro de M. fryanus em plantios de Pinus, e o referido inseto pode ser considerado uma nova praga dessa espécie florestal. Detalhes das características morfológicas e biológicas, danos e possíveis métodos de controle de M. fryanus são discutidos.
\end{abstract}

Palavras-chave: Praga florestal, praga de raiz, pinheiro e Insecta.

\section{OCCURRENCE OF Migdolus fryanus (COLEOPTERA: CERAMB YCIDAE) IN Pinus caribaea hondurensis PLANTATIONS}

\begin{abstract}
Larvae of Migdolus fryanus Westwood (Coleoptera: Cerambycidae) were found damaging roots of young plants of P. caribaea hondurensis (Sénéel) Barr. \& Golf. in the State of São Paulo, Brazil. This fact increases the importance of this species because the damages have been increasing in forest species specially in eucalyptus plantations. This is the first record of $\boldsymbol{M}$. fryanus in pine plantations and this insect can be considered a pest of pine plants. Details on the morphology and biological characteristics, damage and possible control methods to M. fryanus are discussed.
\end{abstract}

Key-words: Forest pest, root pest, tropical pine and Insecta.

Besouros do gênero Migdolus (Coleoptera: Cerambycidae) são nativos da América do Sul, com 10 espécies registradas no Brasil atacando várias culturas agrícolas, principalmente plantações de cana-de-açúcar, sendo Migdolus fryanus Weswood a espécie mais comum e numerosa (BENTO et al., 1995). Embora consideradas altamente polífagas, são escassas as informações sobre espécies de Migdolus em espécies florestais de importância econômica. O primeiro registro de uma espécie desse gênero atacando raízes de Eucalyptus spp. ocorreu no município de Tamoio, SP, em 1943, sendo identificada como Migdolus morretesi Lane (FONSECA, 1958).
Indivíduos de $M$. fryanus apresentam dimorfismo sexual, com machos menores e com coloração escura (preta ou castanho-escura) e bons voadores. No entanto, as fêmeas são maiores e de coloração castanhoavermelhada e, por apresentarem asas atrofiadas, são incapazes de voar, o que limita consideravelmente sua dispersão (BENTO et al., 1995). Trata-se de uma espécie holometábola (ovo, larva, pupa e adulto), com seus ovos de coloração branco-leitosa e colocados a diferentes profundidades no solo. As larvas são, também, branco-leitosas, com o formato típico de uma coleobroca da família Cerambycidae, e podem atingir até $6 \mathrm{~cm}$ de comprimento. Essa é a fase mais prejudicial

\footnotetext{
${ }^{1}$ Recebido em 20.01.2004 e aceito para publicação em 25.11.2004.

${ }^{2}$ Departamento de Produção Vegetal, FCA/UNESP - Campus de Botucatu, Caixa Postal 237, CEP 18603-970 Botucatu, SP. - E-mail: <cwilcken@fca.unesp.br>.
} 
pelo fato de as larvas penetrarem no solo até $4 \mathrm{~m}$ de profundidade em busca de raízes das plantas para se alimentarem. Adultos do gênero Migdolus não se alimentam, e a longevidade dos seus adultos varia com o sexo, com os machos vivendo de quatro a sete dias e as fêmeas, de sete a 38 dias. Em virtude de as fêmeas terem asas não-funcionais, são incapazes de voar e saem para a superfície apenas durante o período de acasalamento, enterrando-se novamente após a cópula. Cada fêmea põe de 14 a 45 ovos no solo, em diferentes profundidades. (BENTO et al., 1995).

O ciclo biológico de espécies do gênero Migdolus é pouco conhecido, com a duração de sua fase larval estimada em dois a três anos. O número de larvas desse cerambicídeo é maior na camada superficial do solo (0 a $30 \mathrm{~cm})$, com danos mais acentuados nos meses de abril a setembro, ou seja, nos períodos mais secos do ano, e diminuem com o início das chuvas, quando ocorre a revoada de seus adultos (outubro a fevereiro) (BENTO et al., 1995).

Em 5 de julho de 2000 foi constatada a ocorrência de larvas de M. fryanus (Figura 1) em uma área de 33,46 ha de $P$. caribaea var. hondurensis (Sénéel) Barr. \& Golf., no município de Agudos, SP. O ataque atingiu 10 ha, em que as larvas danificaram mudas de 10 meses de idade, com perdas acima de $25 \%$ das mudas plantadas. O dano observado foi a destruição das raízes principais e secundárias, em virtude de as larvas de M. fryanus se locomoverem em espiral pelo substra-

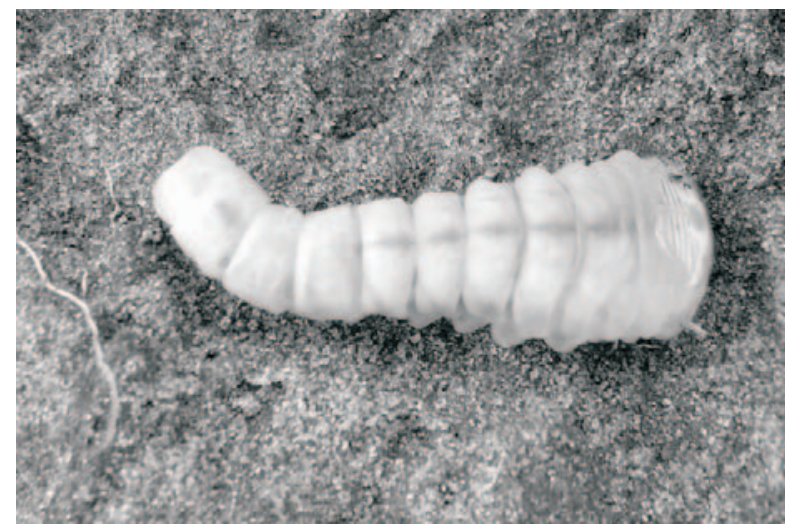

Figura 1 - Larva de Migdolus fryanus (Coleoptera: Cerambycidae). Agudos SP.

Figure 1 - Larvae of Migdolus fryanus (Coleoptera: Cerambycidae), Agudos, State of São Paulo, Brazil.

R. Árvore, Viçosa-MG, v.29, n.1, p.171-173, 2005 to, alimentando-se da casca e da parte lenhosa das raízes. Esse dano causa, inicialmente, a clorose das acículas, seguida pelo secamento e morte das mudas (Figura 2), com sintomas semelhantes àqueles causados em plantios de eucalipto. A mortalidade das mudas tende a ser maior na época seca quando as plantas de Pinus não encontram a umidade necessária para suportar os danos no sistema radicular e, também, pelo fato de esse plantio estar situado em solo de textura arenosa.

Larvas de M. fryanus foram trazidas ao laboratório e colocadas em vasos com mudas de Pinus, mas sem conseguir obter adultos. Adultos dessa espécie foram capturados na mesma área em novembro de 2000, com armadilhas iscadas com feromônio sexual sintético e estão depositados no museu entomológico do Dep. de Produção Vegetal, da Faculdade de Ciências Agronômicas, da Universidade Estadual Paulista (UNESP), campus de Botucatu, Botucatu, SP. Alguns exemplares foram enviados ao Dr. Ubirajara Martins, do Museu de Zoologia da Universidade de São Paulo, para confirmação da identificação.

A ocorrência de $M$. fryanus em plantios de eucalipto no Estado de São Paulo tem aumentado desde 1998, mas este é o primeiro relato dessa espécie em Pinus. O número reduzido de registros de $M$. fryanus nas últimas décadas pode ser devido ao uso, no passado,

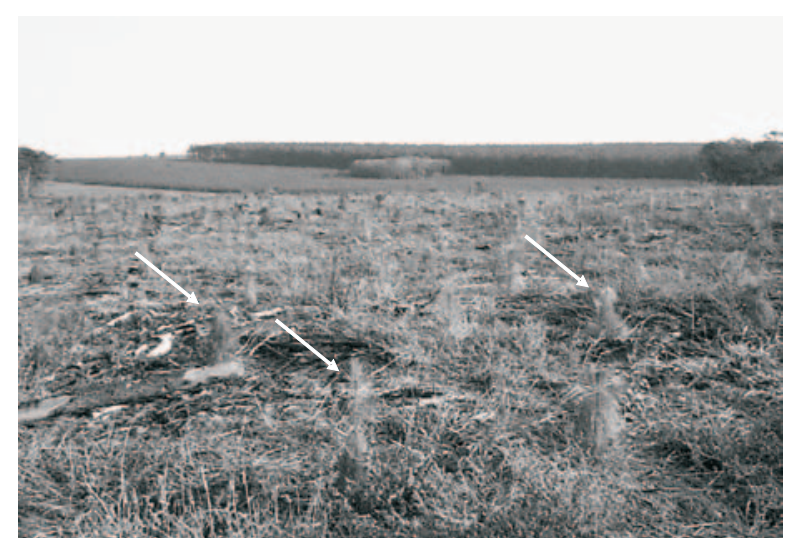

Figura 2 - Área atacada por Migdolus fryanus (Coleoptera: Cerambycidae), com plantas de Pinus caribaea hondurensis com acículas secas. Agudos, SP.

Figure 2-Area attacked by Migdolus fryanus (Coleoptera: Cerambycidae), with plants of Pinus caribaea hondurensis with dry needles. Agudos, State of São Paulo, Brazil. 
de inseticidas clorados, principalmente aldrin e heptacloro, para o controle preventivo de cupins e de outras pragas subterrâneas em diversas culturas agrícolas (MARICONI, 1971). Como esses inseticidas tinham período residual de controle longo no solo, isso pode constituir um dos motivos do baixo nível de infestação da praga em estudo. No entanto, a degradação dos resíduos desses produtos ao longo do tempo pode ter permitido à praga aumentar lentamente sua população. Além disso, a longa rotação dos plantios de Pinus pode favorecer a multiplicação de M. fryanus, com aumento dos danos em plantios novos.

A ocorrência de $M$. fryanus tende a aumentar pela proibição de inseticidas clorados em áreas agrícolas e florestais há mais de 10 anos. Além disso, alterações no manejo florestal, como reforma, após o primeiro corte, das florestas de eucalipto e a rotação de florestas de Pinus em períodos mais curtos, devem favorecer essa praga.

M. fryanus tem sido monitorado com armadilhas de solo iscadas com feromônio sexual, e tentativas de controle, através da coleta massal dos machos com essas armadilhas, têm sido feitas em áreas cultivadas com cana-de-açúcar. Entretanto, o controle químico, através do uso de endosulfan e fipronil, aplicados no sulco ou cova de plantio, tem sido o método predominante.
O monitoramento e controle de $M$. fryanus são pouco conhecidos, sendo restritos à cultura da canade-açúcar. Portanto, é necessário o desenvolvimento de pesquisas para minimizar o potencial de danos dessa espécie, em espécies florestais. Como recomendação, sugere-se que estudos sejam realizados visando à utilização de armadilhas de feromônio em plantios de eucalipto e Pinus para determinar as áreas de reforma que poderão estar mais suscetíveis ao ataque desse inseto. Além disso, deve-se realizar a avaliação de inseticidas de uso florestal para o controle de M. fryanus, principalmente em situações emergenciais, com prioridade para produtos de baixa toxicidade e reduzido impacto ambiental.

\section{REFERÊNCIAS BIBLIOGRÁFICAS}

BENTO, J.M.S. et al. Migdolus: biologia, comportamento e controle. Salvador: 1995. 58 p.

FONSECA, J.P. Migdolus morretesi Lane (Coleóptero: Anoplodermidae) uma eventual broca da cana-de-açúcar e do eucalipto. Archivos do Instituto Biológico, v. 25, p. 27-40, 1958.

MARICONI, F.A.M. Inseticidas e seu emprego no combate às pragas. 3.ed. São Paulo: A Gazeta Maçônica, 1971, 305 p. 
